\title{
Research on Corrosion Fatigue Crack Propagation Behavior of Welded Joints of A7N01P-T4 Aluminum Alloys
}

\author{
Jia Chen ${ }^{1,2, a}$, Jian $\mathrm{Xu}^{1, \mathrm{~b}}$, Maojuan Zhao ${ }^{3, \mathrm{C}^{*}}$, Guoqing Gou ${ }^{2, \mathrm{~d}}$ \\ ${ }^{1}$ Chengdu Industry and Trade College, Chengdu 611731, China \\ ${ }^{2}$ School of Materials Science and Engineering, Southwest Jiaotong University, Chengdu \\ 610031, China
}

${ }^{3}$ Chengdu University, College of information science and engineering, Chengdu 610100, China

a15574423@qq.com; bianxu1021@126.com;**1160698685@qq.com

dgouguoqing1001@163.com

Keywords: High Speed Train; Corrosion Fatigue; A7N01P-T4 Aluminum Alloy

Abstract: Corrosion fatigue crack propagation behavior of welded joints a of A7N01P-T4 aluminum alloys were investigated. The corrosion fatigue crack propagation rate of base metal is higher than that of the heat-affected zone and the welding seam has a better corrosion fatigue resistance.

\section{Introduction}

Corrosion fatigue failure is one of failure forms of structures which under the service of cyclic load with corrosive environment[1].This failure form often occurs in $2 \mathrm{xxx}, 7 \mathrm{xxx}$ series aluminum alloys of aircraft, vehicles and other important transportation structures and more than half of failures were in correlation with corrosion fatigue [3 6]. The fatigue life of structures in corrosion environment is much shorter than that of in air, especially when the applied stress is much closer to the fatigue limit of the structures.

This paper reports the results from our investigation on the corrosion fatigue properties especially on the crack propagation behavior.

\section{Material and experimental techniques}

The experiment materials are A7N01P-T4aluminum alloy plates ( $\mathrm{P}$ stands for plate and T4 stands for a steady state after solution treatment and natural cooling according to ISO XXXX[35]). Welding was performed by the Metal Inert-Gas (MIG) technique with a PHOENIX 421 EXPERT welding machine. The welding wires are ER5356 of $1.6 \mathrm{~mm}$ diameter. The chemical composition of the A7N01P Al alloy base metal, A7N01P, and the welding wire are listed in Table 1. The welding parameters are listed in Table 2. To remove the oxides and reduce the porosity of the joints, the surface of the alloy was chemically cleaned before welding.

Table 1 Chemical composition of base metal and welding wire

\begin{tabular}{|l|c|c|c|c|c|c|c|c|c|}
\hline Material & $\mathrm{Zn}$ & $\mathrm{Mg}$ & $\mathrm{Cu}$ & $\mathrm{Mn}$ & $\mathrm{Ti}$ & $\mathrm{Si}$ & $\mathrm{Fe}$ & $\mathrm{Cr}$ & $\mathrm{Al}$ \\
\hline A7N01P-T4 & $\begin{array}{l}4.0 \sim 5 . \\
0\end{array}$ & $\begin{array}{c}1.0 \sim 1 \\
.8\end{array}$ & 0.10 & $\begin{array}{c}0.20 \sim 0 . \\
70\end{array}$ & $\begin{array}{c}0.01 \sim 0 \\
.06\end{array}$ & 0.35 & 0.40 & $\begin{array}{c}0.06 \sim 0 \\
.20\end{array}$ & Bal. \\
\hline ER5356 & 0.10 & $\begin{array}{c}4.5 \sim 5 \\
.5\end{array}$ & 0.1 & $\begin{array}{c}0.05 \sim 0 . \\
20\end{array}$ & 0.2 & 0.25 & 0.10 & -- & Bal. \\
\hline
\end{tabular}

Note: 1. The chemical composition of A7N01P-T4 refers to GB/T 16475-2008: Temper designation system for wrought aluminum and aluminum alloy. 2. The chemical composition of ER5356, which is similar to filler metal, was listed for future analysis. 
Corrosion fatigue crack propagation experiment was performed according to ISO 12108: Metallic materials-Fatigue experimenting - Fatigue crack propagation method. The specimen in this paper was improved from single edge notched tension specimen(SENT) in ISO 12108. The specimens of base metal and welding joints was machined along Y-X (X stands for the direction paralleling to the welding line and $\mathrm{Y}$ stands for the direction perpendicular to the welding line). BM, HAZ and WM respectively stand for the specimen in base metal, the heated-affected zone and the welded joint. Sampling method and dimension of corrosion fatigue specimen are shown in fig.1.

(a)

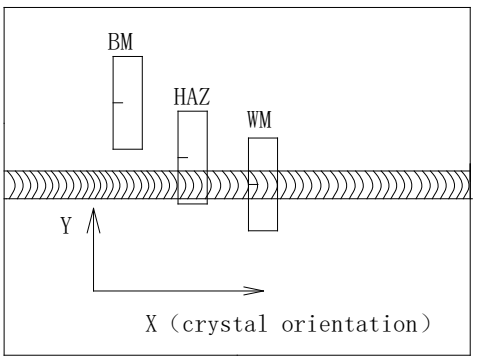

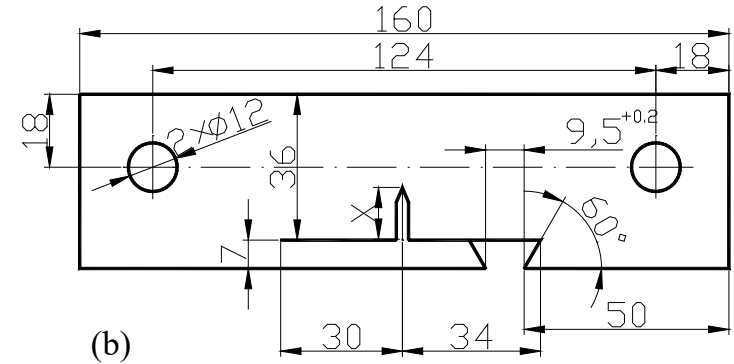

(b)

Fig. 1 Sampling method and dimension of corrosion fatigue specimen (a)Sampling method (b)dim ension of corrosion fatigue specimen

Specimens in the direction of Y-X (see Fig.1) for corrosion fatigue cracking experimenting were cut and machined from the BM, HAZ and WM of the welded joints according to ISO 7539-6:2003 and ISO 7539-8:2000. A notch was cut at the edge of each specimens with the same way. The presetting notch was $1 \sim 2 \mathrm{~mm}$ long and the pre-crack length was $1 \sim 2 \mathrm{~mm}$ long.

To assure the accuracy of the experimenting data, only the region of interest of each sample was immersed into the solution during experimenting, and the rest of the sample surface was masked with the BONLE type cyanoacrylate adhesive glue. The sharp incision and the extensometers were also isolated using glue and then covered with epoxy. A paper cup was used as the corrosion solution container. The entire set up for the corrosion fatigue cracking experimenting is shown in Fig. 2. The specimens were clamped through two fixtures.

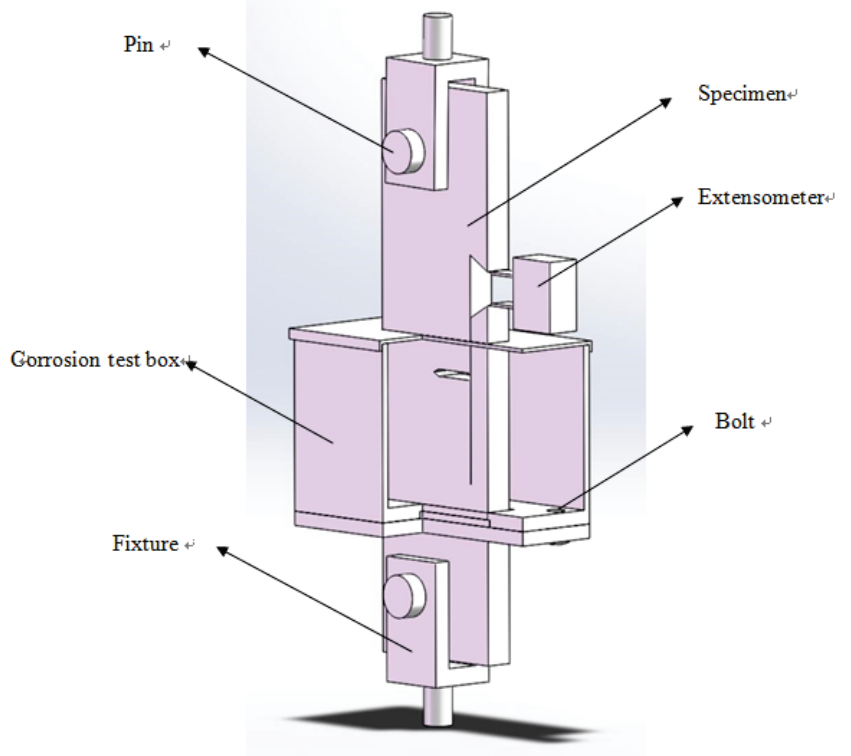

Fig.2 Clamping sketch of the specimen 


\section{Results and discussion}

The relationship of corrosion fatigue crack propagation rate da/dN vs. stress intensity range $\Delta \mathrm{K}$ were shown in Fig.3 and Table 2. In order to get the statistics disciplinarian and trend disciplinarian, the seven points incremental polynomial method was used. The Paris equations (1) was used to process the measured data.

Where $\mathrm{da} / \mathrm{dN}$ is the fatigue crack propagation rate; $\Delta \mathrm{K}$ is the stress intensity range; $\mathrm{C}, \mathrm{m}$ is the material constants.
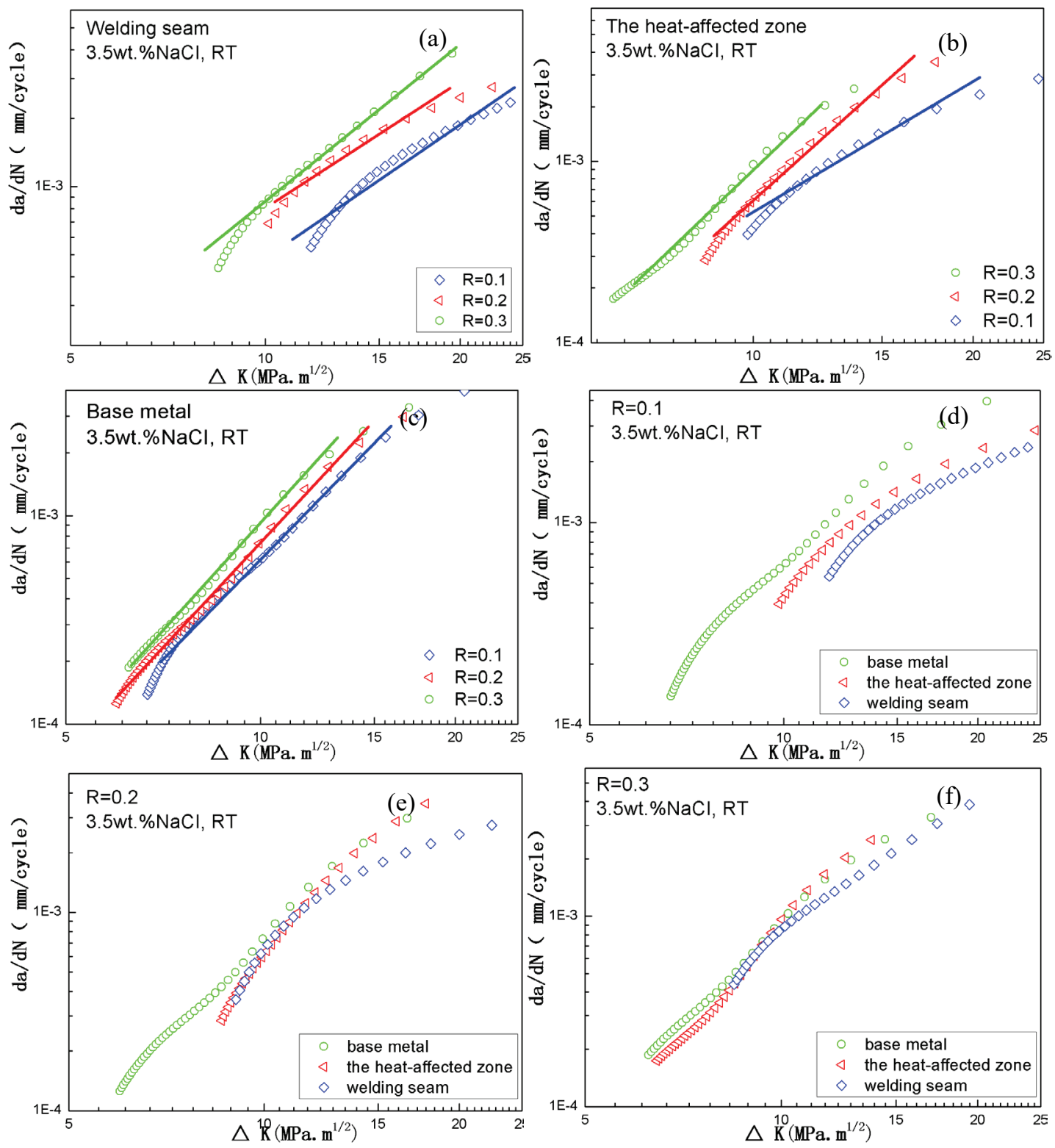

Fig. 3 da/dN versus $\Delta K$ curves of base metal and welded joint: (a) corrosion fatigue crack propagation rate(CFCGR) curves of welding seam under different stress ratio, (b) CFCGR curves of the heat-affected zone under different stress ratio, (c) CFCGR curves of base metal under different stress ratio, (d) CFCGR curves of welding seam, the heat-affected zone and base metal under stress ratio $R=0.1$, (e) CFCGR curves of welding seam, the heat-affected zone and base metal under stress ratio $R=0.2,(f) C F C G R$ curves of welding seam, the heat-affected zone and base metal under stress ratio $R=0.3$. 
Table2 Fitting parameters of Paris formula of base metal and welded joint

\begin{tabular}{|c|c|c|}
\hline Condition & $\mathrm{C}$ & $\mathrm{m}$ \\
\hline WM, $\mathrm{R}=0.1$ & $6.08 \times 10^{-7}$ & 3.0001 \\
\hline Welded seam, $\mathrm{R}=0.2$ & $2.04 \times 10^{-5}$ & 1.5363 \\
\hline Welded seam, $\mathrm{R}=0.3$ & $1.18 \times 10^{-6}$ & 2.6419 \\
\hline HAZ, $\mathrm{R}=0.1$ & $2.74 \times 10^{-6}$ & 2.26123 \\
\hline $\begin{array}{c}\text { The heat-affected zone, } \\
\mathrm{R}=0.2\end{array}$ & $1.30 \times 10^{-7}$ & 3.65022 \\
\hline $\begin{array}{c}\text { The heat-affected zone, } \\
\mathrm{R}=0.3\end{array}$ & $1.39 \times 10^{-7}$ & 3.79517 \\
\hline Base metal, $\mathrm{R}=0.1$ & $4.48 \times 10^{-6}$ & 2.02025 \\
\hline Base metal, $\mathrm{R}=0.2$ & $4.24 \times 10^{-7}$ & 3.2281 \\
\hline Base metal, $\mathrm{R}=0.3$ & $6.008 \times 10^{-7}$ & 3.14431 \\
\hline
\end{tabular}

From the results, corrosion fatigue crack propagation rate of BM, HAZ and WM increased with the increase of stress ratio $\mathrm{R}$. The propagation rate of BM was the highest, the propagation rate of HAZ was the medium and the WM was the lowest.

\section{Conclusion}

The behavior of corrosion fatigue crack propagation of base metal and welded joint of A7N01P-T4 aluminum alloy in $3.5 \% \mathrm{wt} . \mathrm{NaCl}$ under the different stress ratio was studied in this paper. On the basis of the experiment results, the conclusions are drawn as follows:

(1) The welding seam of A7N01P-T4 aluminum alloy has a better corrosion fatigue resistance than that of the heat-affected zone in $3.5 \% \mathrm{wt} . \mathrm{NaCl}$ and base metal has the worst corrosion fatigueresistant performance.

\section{References}

[1] Lv Shengli, ZHANG youhong, LV guozhi. research and evaluation on corrosion damage of aluminium alloy structure.Xian, Northwestern Polytechnic University Press, 2009.169.

[2] H. Seifert, S. Ritter, Corrosion Science 2016.

[3] GOU Guoqing, HUANG Nan, CHEN Hui, LI Da, MENG Lichun. Analysis on corrosion behavior of welded joint of A7N01S-T5 aluminum alloy for high-speed train. Transaction of the China Welding Institution. 2011,32 (10) : 17-20.

[4] Frederic Menan, Gilbert Henaff. Influence of frequency and exposure to a saline solution on the corrosion fatigue crack propagation behavior of the aluminum alloy 2024[J]. Intenational Journal of Fatigue, 2009, 31: 1684-1695. http://dx.doi.org/10.1016/j.ijfatigue.2009.02.033

[5] U.Zupanca, J.Grumb. Effect of pitting corrosion on fatigue performance of shot-peened aluminium alloy 7075-T651[J]. Journal of Materials Processing Technology, 2010, 210: 1197-1202. http://dx.doi.org/10.1016/j.jmatprotec.2010.03.004

[6] ZHANG Zhenggui,ZHOU Zhaoyuan, LIU Changyong. Corrosion fatigue failure analysis of high-strength aluminum alloy [J] .Journal of Chinese Society for Corrosion and Protection, 2008, 28(1): 48-51. 